\title{
STRATEGI PENGEMBANGAN PROFIL KAPABILITAS MANAJEMEN PERUSAHAAN DALAM MENGHADAPI TURBULENSI LINGKUNGAN BISNIS YANG SEDANG BERLANGSUNG SAAT INI DI SALAH SATU DIVISI PT. $X$
}

\author{
Harrie Lutfie \\ Dosen D3 Pemasaran Business School, Telkom University; harrie@ypt.or.id
}

\begin{abstract}
Abstrak
Hadirnya operator-operator baru baik yang berskala Nasional maupun Internasional bidang Telekomunikasi dan di era persaingan bisnis perusahaan menuntut adanya suatu perubahan rancangan strategi bisnis perusahaan untuk mengantisipasi gejolak lingkungan bisnis perusahaan. Strategi yang digunakan melalui profil manajer, kompetensi manajemen, iklim manajemen, dan kapabilitas manajemen. Oleh karena itu, Perlu dilakukan trial and error assessment profil kapabilitas manajemen perusahaan di divisi tertentu untuk di evaluasi dan dikembangkan ke divisi lainnya
\end{abstract}

Kata Kunci : Bisnis, Iklan, Kapabilitas, Kompetensi, Manajemen, Profil

\section{PENDAHULUAN}

Hadirnya operator-operator baru baik yang berskala Nasional maupun Internasional bidang Telekomunikasi dan di era persaingan bisnis perusahaan menuntut adanya suatu perubahan rancangan strategi bisnis perusahaan untuk mengantisipasi gejolak lingkungan bisnis perusahaan. PT $X$ dalam hal ini melakukan penataan ulang kembali strategi bisnisnya melalui transformasi perusahaan yang terdiri atas transformasi bisnis (TIME), infrastruktur, System \& prosedur, dan transformasi organisasi dan budaya perusahaan.

Transformasi yang dilakukan oleh PT $X$ dalam rangka meningkatkan kapabilitas internal organisasi dan manajemen perusahaan untuk menghadapai turbulensi lingkungan bisnis. Gejolak lingkungan bisnis menuntut adanya perubahan kapabilitas internal organisasi dan manajemen perusahaan agar dapat bersaing secara profesional. Salah satu bentuk kesiapan bersaing dalam mengantisipasi turbulensi lingkungan adalah dengan melakukan suatu analisa profil kapabilitas manajemen perusahaan meliputi profil manajer, kompetensi mgt, iklim manajemen, dan kapasitas manajemen. Sedangkan gejolak lingkungan yang perlu diperhatikan adalah gejolak sosial politik, ekonomi pasar, dan technology.

Pada umumnya perusahaan kurang memperhatikan tingkat (level) turbulensi lingkungan bisnis kondisi saat ini dan masa mendatang, perusahaan sering melakukan transformasi namun apakah transformasi tersebut dapat mengantisipasi tuntutan lingkungan bisnis yang sedang terjadi?. Hal ini penting untuk diketahui guna mengantisipasi setiap perubahan turbulensi lingkungan tentunya dengan strategi yang tepat melalui identifikasi profil kapabilitas manajemen perusahaan.

Apabila kita perhatikan skala turbulensi lingkungan (tuntutan lingkungan bisnis) terdiri atas lima level turbulensi:

- Level 1

Adalah Repetitiive penetapan market place berdasarkan historical, dengan demikian pada level ini pekerjaan lebih bersifat pengulangan saja.

- Level 2

Adalah expanding pada level ini terjadi perubahan secara incremental dan sangat lambat, ukuran keberhasilan terhadap perubahan ini berdasarkan atas respon pergerakan kompetitor saja. 
- Level 3

Changing, perubahan yang terjadi cepat berdasarkan akstrapolasi dimana pelayanan didasarkan atas kebutuhan kustomer saja.

- Level 4

Discontinous, pada level ini perubahan bersifat discontinous namun predictable.
- $\quad$ Level 5

Surprising, perubahan yang terjadi sangat cepat dan sulit untuk diperkirakan sebelumnya.

Tabel dibawah menunjukan skala dari level turbulensi lingkungan.

TABEL 1.1

SAKALA LEVEL TURBULENSI LINGKUNGAN

\begin{tabular}{|c|c|c|c|c|c|}
\hline $\begin{array}{c}\text { Environmenttal } \\
\text { Turbulence }\end{array}$ & Repetitive & Expanding & Changing & Discontinous & Surprising \\
\hline Complexity & National Economic & & $\begin{array}{c}\text { Regional } \\
\text { Technological }\end{array}$ & & $\begin{array}{c}\text { Global } \\
\text { Socio-Political }\end{array}$ \\
\hline Familiarity of Evens & Familiar & Extrapolable & & $\begin{array}{c}\text { Discontinous } \\
\text { Familiar }\end{array}$ & $\begin{array}{c}\text { Discontinous } \\
\text { Novel }\end{array}$ \\
\hline Rapidity of Change & Slower than Response & & $\begin{array}{l}\text { Compatable } \\
\text { To Response }\end{array}$ & & $\begin{array}{c}\text { Faster Than } \\
\text { Response }\end{array}$ \\
\hline Visibility of Future & Recurring & Forcastable & Predictable & $\begin{array}{c}\text { Partially } \\
\text { Predictable }\end{array}$ & $\begin{array}{c}\text { Unpredictable } \\
\text { Surprises }\end{array}$ \\
\hline
\end{tabular}

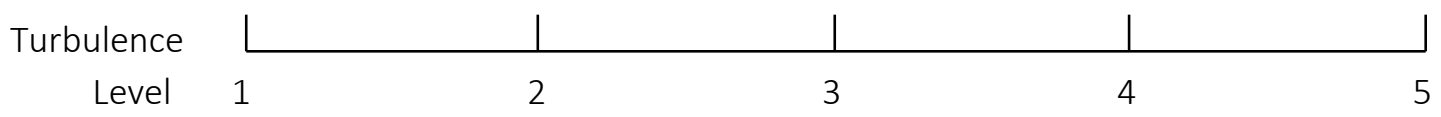

Dalam hal ini pengukuran yang akan dilaksanakan untuk turbulensi lingkungan bisnis adalah:

a) Sosial politik (seperti tekanan pemerintah, tekanan lingkungan, dan iklim sosial).

b) Ekonomi pasar terdiri atas dif strategi pemasaran, kompleksitas persaingan, tekanan pelanggan, tekanan suplier, rasio demand supply, ancaman jasa subtitusi dan key sucess factor

c) Teknologi terdiri atas product life cycle, kecepatan teknologi, keragaman teknologi, key sucess factor.

Dengan merujuk pada kondisi turbulensi tersebut diatas bahwa salah satu penyebab perusahaan sering kali mengalami kegagalan adalah kurangnya perhatian dalam mendefinisikan level turbulensi lingkungan bisnisnya, sehingga ketika proses transformasi berjalan belum tentu sesuai dengan profil kapabilitas manajemen perusahaan yang diharapkan. Sering terjadi gap yang cukup besar antara tuntutan lingkungan bisnis dengan kapabilitas manajemen perusahaan dapat menjadikan hambatan dalam meng create revenue perusahaan juga dapat menurunkan performansi. Ini salah satu penyebab permasalahan transformasi yang kurang melihat level turbulensi lingkiungan bisnis.

Adapun tujuan penelitian ini adalah untuk mengingatkan kembali kepada manajemen perusahaan bahwa dalam mengantisipasi turbulensi lingkungan bisnis perusahaan, perlu dilakukan penyesuaian strategi bisnis perusahaan dalam bentuk transformasi perusahaan. 
Transformasi ini perlu dilakukan guna mengikuti perkembangan bisnis, sehingga manajemen perusahaan dapat menyesuaikan profil kapabilitas manajemen perusahaan dengan tuntutan lingkungan bisnis. Dengan mengetahui gejolak lingkungan bisnis pada level tertentu maka dapat diketahui pula respon yang diberikan oleh perusahaan sehingga strategi perusahaan kedepan dapat dilakukan penyesuain dengan level yang sesuai dengan gejolak lingkungan bisnis (proses match up), kemudian dicari solusi untuk mengatasi kelemahan-kelemahan dari profil kapabilitas manajemen perusahaan sebagai acuan dalam pengambilan keputusan oleh manajemen perusahaan.

Bahwa untuk melakukan transformasi perusahaan tentunya harus memperhatikan gejolak lingkungan bisnis. Tuntutan lingkungan bisnis ini sangat penting karena mempengaruhi strategi perusahaan kedepan.

Perubahan lingkungan eksternal menuntut respon perubahan strategi perusahaan. Pengelolaan sistem manajemen perusahaan merupakan salah satu yang terkena dampak perubahan tersebut seperti halnya yang dialami oleh para manajer fungsi dan manajer umum perusahaan yang dilanda perubahan lingkungan dengan tingkat turbulensi yang cepat, dan tingkat frekuensi serta intensitas yang tinggi. Akibat dari perubahan yang begitu cepat dengan intensitas yang tinggi, maka dalam pengelolaan sistem manajemen PT $X$ perlu ditemukenali perubahan-perubahan yang sedang terjadi dan bagaimana upaya untuk mengantisipasinya serta dampak yang timbul akibat perubahan tersebut.

Untuk menemukan perubahan-perubahan tersebut dapat dilihat isu-isu strategis perubahan lingkungan bisnis Telekomunikasi di Indonesia, seperti isu perubahan lingkungan eksternal, bagaimana cara yang tepat untuk memilih arah pengembangan perusahaan dari alternatif-alternatif yang ada, namun hal tersebut belum sepenuhnya dapat dipahami misalnya:

a) mencari standar performansi yang optimal,

b) menciptakan hubungan strategis dengan pelanggan- pelanggan kunci

c) memanfaatkan teknologi secara efektif untuk memuaskan kebutuhan-kebutuhan strategis pelanggan.

d) Sampai dengan saat ini kita beleum melihat bahwa transformasi perubahan sebagai dampak adanya tuntutan lingkungan

\section{Tujuan Penelitian}

Tujuan dari kajian ini adalah untuk:

1) Menemukenali sejauh mana gejolak lingkungan bisnis (turbulensi level) dapat direspon oleh kapabilitas manajemen perusahaan sat ini dan masa mendatang.

2) Analisa dan evaluasi terhadap profil kapabilitas manajemen perusahaan kondisi saat ini dan yang diharapkan mendatang.

3) Menentukan kekuatan dan kelemahan terhadap profil kapabilitas manajemen perusahaan yang sesuai dengan gejolak lingkungan bisnis.

4) Menentukan strategi kedepan setelah diketahui kekuatan dan kelemahan dari profil kapabilitas manajemen perusahaan untuk mengantisipasi perubahan lingkungan bisnis.

5) Melakukan proses match up terhadap profil kapabilitas manajemen perusahaan berdasarkan gejolak lingkungan bisnis.

6) Membuat program kerja sebagai penjabaran dari strategi perusahaan untuk mengantisipasi gejolak lingkungan bisnis.

\section{Batasan Penelitian}

Berdasarkan latar belakang di atas batasan penelitian ini adalah:

1) Obyek yang akan diteliti ada pada Level Manajemen Umum (General Management) 
yang merupakan Manajemen Puncak (Top Management) Divisi tertentu.

2) Obyek berikutnya yang akan diteliti ada pada Level Manajemen Fungsi (Management Functional) merupakan Level kedua pada Divisi tertentu, yang merupakan manajer fungsi.

3) Responden yang dipilih khusus untuk Turbulensi Lingkungan Usaha berasal dari sumber internal dan eksternal perusahaan yang dianggap mewakili sebagai expert.

4) Untuk responden Kapabilitas Internal Organisasi dan Manajemen Perusahaan berasal dari sumber internal perusahaan yang dianggap mewakili sebagai expert dibidangnya.

5) Jangka Pendek penelitian yang dimaksud disini adalah satu tahun (kondisi saat ini), sedangkan trend turbulensi lingkungan adalah sampai dengan lima tahun.

6) Lokasi yang dijadikan sebagai obyek penelitian adalah PT TELKOM Divisi tertentu.

\section{Rumusan Penelitian}

Adapun rumusan masalah sebagai berikut:

1) Bagaimana cara yang tepat untuk memilih arah pengembangan perusahaan dari alternatif-alternatif yang ada?

2) Bagaimana menemukenali Profil Manajemen Fungsi (Functional Management) dan Profil Manajemen Umum (General Management) serta bagaimana cara memanfaatkan kapabilitas dari hal tersebut diatas agar menjadi handal untuk menghasilkan produktivitas dan memberikan margin kontribusi yang tinggi terhadap perusahaan, serta bersikap fleksibilitas terhadap perubahan lingkungan perusahaan yang terjadi?

\section{KAJIAN TEORI}

\section{Kapabilitas Manajemen}

Belum banyak literatur maupun ahli yang membas secara khusus mengenai konsep kapabilitas manajemen. Paradigma baru mengenai manajemen organisasi sebagai akibat dari dinamisasi lingkungan dan tuntutan bagi pengelola organisasi untuk bersikap adaptif dan memprioritaskan organisasi pada kinerja (performance) secara utuh yang tidak hanya dari sudut pandang individu maupun pemimpin, tetapi juga pada kemampuan manajemen di organisasi tersebut. kapabilitas manajemen kurang lebih dapat digambarkan seperti berikut:

Capability management aims to balance economy in meeting current operational requirements, with the sustainable use of current capabilities, and the development of future capabilities, to meet the sometimes competing strategic and current operational objectives of an enterprise. Accordingly, effective capability management:

- Assists organizations to better understand, and effectively integrate, re-align and apply the total enterprise ability or capacity to achieve strategic and current operational objectives; and

- Develops and provides innovative solutions that focus on the holistic management of the defined array of interlinking functions and activities in the enterprise's strategic and current operational contexts (www.en.wikipedia.com)

Kapabilitas manajemen pada hakikatnya adalah upaya yang dilakukan perusahaan untuk menyeimbangkan kondisi perusahaan pada saat sekarang ini dengan memanfaatkan potensi dan kemampuan yang dimiliki secara berkelanjutan dan melakukan pengembangan organisasi untuk kegiatan dimasa yang akan datang. 
Dalam 2012 Australian Management Capability Index (2012:7) disebutkan bahwa:

Management capability refers to the potency of an organisation's collective management competencies as they can be applied to achieve desired outcomes. Management capability, therefore, does not simply refect the total sum of a management team's competencies or required abilities. rather, management capability describes how effectively the management team puts into practice its combined competencies to deliver business results.

Keberhasilan kapabilitas manajemen melibatkan segenap unsur yang ada dalam organisasi, dari mulai kepemimpinan, kemampuan pegawai, keuangan, dan unsur lain yang saling bersinergi. Dari hasil survey yang dilakukan AMCl (Australian Management Capability Index), ada 10 faktor penentu keberhasilan penerapan kapabilitas manajemen beserta hierarkinya pengaruhnya.

TABEL 1.2

AUSTRALIAN MANAGEMENT CAPABILITY INDEX

\begin{tabular}{|c|c|c|c|c|c|}
\hline & Category & $\mathrm{AMCl}$ & & & \\
\hline $\begin{array}{c}\text { TINGKAT } \\
\text { TURBULENSI }\end{array}$ & $\begin{array}{c}\text { BERULANG } \\
\text { (Tidak Berubah) }\end{array}$ & $\begin{array}{c}\text { EKSPANSI } \\
\text { (Perubahan } \\
\text { Inkremental yang } \\
\text { Lambat) }\end{array}$ & $\begin{array}{l}\text { BERUBAH } \\
\text { (Perubahan } \\
\text { Inkremental } \\
\text { yang Cepat) }\end{array}$ & $\begin{array}{l}\text { DISKONTINU } \\
\text { Perubahan } \\
\text { Diskontinuitas } \\
\text { yang dapat } \\
\text { diprediksi }\end{array}$ & $\begin{array}{c}\text { Surprising } \\
\text { Perubahan } \\
\text { Diskontinuitas } \\
\text { yang tidak dapat } \\
\text { diprediksi }\end{array}$ \\
\hline AGRESIFITAS & STABIL & REAKTIF & ANTISIPASI & ENTEPRENIR & KREATIF \\
\hline $\begin{array}{l}\text { DERAJAT } \\
\text { PERUBAHAN }\end{array}$ & Not & Inkremental & Inkremental & $\begin{array}{c}\text { Diskontinuitas } \\
\text { Familiar }\end{array}$ & $\begin{array}{c}\text { Diskontinuitas } \\
\text { Baru }\end{array}$ \\
\hline DATABASE & Historis Peniruan & $\begin{array}{c}\text { Historis } \\
\text { Pengalaman }\end{array}$ & Extrapolasi & $\begin{array}{c}\text { Peluang Masa } \\
\text { Depan }\end{array}$ & Kreatifitas \\
\hline $\begin{array}{l}\text { RESPONSIFITAS } \\
\text { DARI KAPABILITAS } \\
\text { GENERAL } \\
\text { MANAJEMEN }\end{array}$ & Melihat Stabil & $\begin{array}{l}\text { Digerakan } \\
\text { Effisiensi }\end{array}$ & Digerakan Pasar & $\begin{array}{l}\text { Digerakan } \\
\text { Lingkungan }\end{array}$ & $\begin{array}{l}\text { Menciptakan } \\
\text { Lingkungan }\end{array}$ \\
\hline $\begin{array}{l}\text { MANAJEMEN } \\
\text { PERUBAHAN }\end{array}$ & Perubahan Kejut & $\begin{array}{c}\text { Adaptif kepada } \\
\text { Perubahan }\end{array}$ & Melihat & $\begin{array}{c}\text { Melihat } \\
\text { Perubahan yang } \\
\text { Berhubungan }\end{array}$ & $\begin{array}{c}\text { Melihat } \\
\text { Perubahan Baru }\end{array}$ \\
\hline
\end{tabular}

\begin{tabular}{llc}
\hline 1 & Visionary and Strategic Leadership & 66.0 \\
\hline 2 & Performance Leadership & 70.5 \\
\hline 3 & Financial Management & 69.1 \\
\hline 4 & People Leadership & 76.8 \\
\hline 5 & Organisation Capability & 66.2 \\
\hline 6 & Application of Technology \& Knowledge & 70.4 \\
\hline 7 & External Relationships & 74.1 \\
\hline 8 & Innovation - Products and Services & 67.3 \\
\hline 9 & Integrity and Corporate Governance & 85.7 \\
\hline 10 & Results and Comparative Performance & 70.9 \\
\hline \multicolumn{2}{c}{ AMCl (Overall) } & $\mathbf{7 1 . 1}$ \\
\hline
\end{tabular}

Dalam pendekatan turbulensi lingkungan menurut H.I. Ansoff dan Patrick A Sullivan dalam Jemsly Hutabarat dan Martani Huseini (2006:46), rumusan sukses strategik kontingensi terdiri dan tiga perubah (variabel) yaitu turbulensi lingkungan, agresivitas strategik serta respons kapabilitas manajemen.

Lebih lanjut, Hutabarat dan Martini Husein menjelaskan bahwa : "Agresifitas Strategik terdiri dan dua bagian yaitu derajat perubahan pergerakan perusahaan di dalam lingkungan dan database yang digunakan dalam pemilihan pergerakan. Sedangkan respons dan kapabilitas manajemen juga terdiri dan dua yaitu responsifitas dan kapabilitas general manajemen dan manajemen perubahan".

Kedua paramater kapabilitas manajemen tersebut dapat dijabarkan seperti pada gambar berikut: 
Perubahan lingkungan bergerak dinamis mengikuti perubahan global akibat adanya kebutuhan masyarakat yang selalu berubah dan ingin dipenuhi. Perusahaan merupakan organisasi terbuka yang menerima masukan (input) dari lingkungan termasuk di dalamnya adalah kebutuhan dan keingingan konsumen yang harus dipenuhi. Disatu sisi hal ini menjadi peluang bagi perusahaan untuk terus dapat mempertahankan diri dan berkembang. Tapi disatu lain, hal ini juga dapat dianggap sebagai ancaman bilamana kebutuhan konsumen tidak dapat diakomodasi dengan baik oleh perusahaan. Ancaman lain adalah dari pesaing atau perusahaan lain yang ada pada level atau posisi yang sama yang terus-menerus bergerak dinamis dan siap bersaing untuk menjadi yang terbaik untuk mendapatkan perhatian dari konsumen. Pergolakan yang cepat akibat perubahan yang terjadi di lingkungan itulah yang disebut dengan turbulensi lingkungan.

Batasan pengertian mengenai turbulensi lingkungan seperti yang dikemukakan oleh Jemsly Hutabarat dan Martani Huseini (2006:46) yakni :

Ukuran dari derajat perubahan (atau diskontiunitas) dan kemampuan untuk diprediksi dari lingkungan perusahaan (termasuk variabel eskternal). Faktor yang mementukan turbulensi lingkungan terdiri dari empat faktor yaitu: kompleksitas dan kejadian, kebiasaan dari kejadianyang berulang (successive), kecepatan memperkirakan kejadian/perubahan serta visibiltas (penglihatan ke depan) dari kejadian.

Pendapat yang berbeda dalam substansi yang sama dikemukakan oleh Husein Umar (2001:196) yakni:

Turbulensi lingkungan merupakan suatu kumpulan ukurandan suatu keterubahan (changeability) dan keterdugaan (predictability) atas lingkungan perusahaan. Changeability terdiri aras kompleksitas lingkungan dan kebaruan relatif dan tantangan berlanjut yang dihadapi perusahaan dalam lingkungannya. Predictability terdiri atas kecetaran perubahan, yaitu rasio keceparan di mana tantangan berganti dalam lingkungan dengan kecepatan respons perusahaan dan kejelasan masa depan, dimana ketepatan dan kesesuaian informasi tentang masa depan berperan penting.

Untuk lebih jelas mengenai penjabaran turbulensi lingkungan dapat dilihat pada gambar berikut ini.

\begin{tabular}{|c|c|c|c|c|c|}
\hline $\begin{array}{c}\text { Tingkat } \\
\text { Turbulensi }\end{array}$ & 1 & 2 & 3 & 4 & 5 \\
\hline Kompleksitas & $\begin{array}{l}\text { Ekonomi } \\
\text { nasional }\end{array}$ & - & $\begin{array}{l}\text { Regional } \\
\text { teknologi }\end{array}$ & - & $\begin{array}{l}\text { Global Sosio- } \\
\text { politik }\end{array}$ \\
\hline Kebiasaan & $\begin{array}{l}\text { Dapat } \\
\text { dikenal }\end{array}$ & Eksplorasi & & $\begin{array}{l}\text { Diskontuinitas } \\
\text { Familiar }\end{array}$ & $\begin{array}{l}\text { Diskontinuitas } \\
\text { baru }\end{array}$ \\
\hline $\begin{array}{l}\text { Kecepatan } \\
\text { Perubahan }\end{array}$ & $\begin{array}{l}\text { Lebih } \\
\text { lambat dari } \\
\text { respons }\end{array}$ & $\begin{array}{l}\text { Dapat } \\
\text { dibandingkan } \\
\text { dengan respon }\end{array}$ & \multicolumn{2}{|c|}{ Lebih cepat dari respon } & $\begin{array}{l}\text { Sangat cepat dari } \\
\text { respons }\end{array}$ \\
\hline $\begin{array}{l}\text { Visibiltas Masa } \\
\text { depan }\end{array}$ & Berulang & Dapat diramalkan & $\begin{array}{l}\text { Dapat } \\
\text { diprediksi }\end{array}$ & $\begin{array}{l}\text { Sebagian dapat } \\
\text { diprediksi }\end{array}$ & $\begin{array}{l}\text { Tidak dapat } \\
\text { diprediksi penuh } \\
\text { kejutan }\end{array}$ \\
\hline
\end{tabular}


Turbulensi erat kaitannya dengan aktivitas memperkirakan atau memprediksi kondisi, kejadian, peristiwa yang akan terjadi di masa mendatang melalui analisis fenomena atau dapat juga melalui data perubahan dari kondisi yang terjadi sekarang lalu memperkirakan perubahan kondisi yang akan terjadi di masa mendatang. Kondisi yang terjadi di masa mendatang merupakan misteri yang tidak bisa tergambarkan secara jelas dan masih sebatas perkiraan atau asumsi yang penuh dengan ketidakpastian. Ketidakpastian ini oleh Cournye, dkk dalam Jemsly Hutabarat dan Martani Huseini (2006:47-48) digolongkan menjadi 4 (empat) tingkatan yakni:

1) Masa depan yang jelas (a clear enough future)

2) Pada tingkatan ini, ramalan tunggal akan masa depan dapat dilaksanakan dengan tepat, ramalan akan cukup terarah pada strategi tunggal.

3) Masa depan berseling/alternatif (alternative future)

4) Pada tingkatan kedua masa depan diramalkan sebagai alternatif atau skenario kebijaksanaan. Kita tidak dapat mengetahui basil yang akan didapatkan, tetapi setidaknya membantu mengembangkan beberapa alternatif.

Lingkup masa depan (a range of future)

Pada tingkatan ketiga, ruang lingkup masa depan yang potensial dapat dildentifikasi. Ruang lingkup didefinisikan oleh batasan nomor dan variabel kunci, tetapi hasil yang terjadi terletak disepanjang perubahan di dalam ruang lingkup tersebut.

Kebenaran yang samar (true ambiguity), Pada tahap keempat ini, kebenaran dapat tergambarkan meskipun masih bersifat samar atau belum ada kepastian tetapi dapat menjadi dasar penentuan strategi.
Turbulensi lingkungan adalah sesuatu yang tidak dapat dihindari dan semua perusahaan pasti akan mengalaminya. Tinggal bagaimana dan upaya apa yang akan dilakukan perusahaan untuk mengantisipasi hal tersebut. maka dari itu diperlukan upaya nyata dan kegiatan yang sistematis bagi perusahaan melalui analisis turbulensi lingkungan sehingga menghasilkan suatu profil turbulensi dana dapat dijadikan sebagai informasi perusahaan dalam mempersiapkan diri secara dini terhadap perubahan tersebut. Deskriptor dalam analisis turbulensi lingkungan adalah sebagai berikut:

1) Perubahan (Changeability)

a) Kompleksitas lingkunga

b) Kebaruan Relatif

2) Perkiraan (Predictability)

a) Kecepatan perubahan

b) Kejelasan masa depan

3) Atribut lainnya

a) Diferensiasi strategi pemasaran

b) Frekuensi strategi pemasaran baru

c) Tekanan pelanggan

d) Permintaan dan kepastian industri

e) Tekanan oleh pemerintah

f) Tekanan oleh environmentalist

g) Diferensiasi produk

h) Frekuensi produk baru

i) Product Life Cycle (PLC)

j) Tingkat perubahan teknologi (TPT)

k) Diversity Competing Technology (DCT)

I) Faktor kesuksesan pemasaran

m) Faktor kesuksesan inovasi

\section{METODE PENELITIAN}

Metode yang digunakan dalam penyelesaian suatu masalah, dalam hal ini metode yang digunakan adalah deskriptif dengan menggunakan penelitian langsung nmelalui survey untuk mengetahui korelasi antara tingkat turbulensi lingkingan bisnis dengan kapabilitas manajemen perusahaan, kemudian hasilnya dilakukan pengolahan data 
dengan menggunakan metode AHP (Aritmatica Hierarchy Prosess). Sebagai tahap akhir dilakukan analisa dengan menggi=unakan metode match up untuk melihat gap yang terjadi sebaga dasar strategi perusahaan dalam menghadapai turbulensi lingkungan bisnis.

\section{PEMBAHASAN}

Berdasarkan kondisi internal dan eksternal perusahaan, maka pendekatan yang dilakukan adalah memberikan respon terhadap tuntutan turbulensi lingkungan bisnis, bila kita lakukan kajian lebih mendalam melalui survey untuk mengetahui tingkat turbulensi lingkungan bisnis dan respon kapabilitas manajemen perusahaan maka hasilnya adalah sebagai berikut :

Dari hasil survey untuk menentukan tingkat turbulensi lingkungan bisnis kondisi saat ini dan mendatang adalah pada level 3.2 dan 4.05.

Gambar dibawah menunjukan level turbulensi.

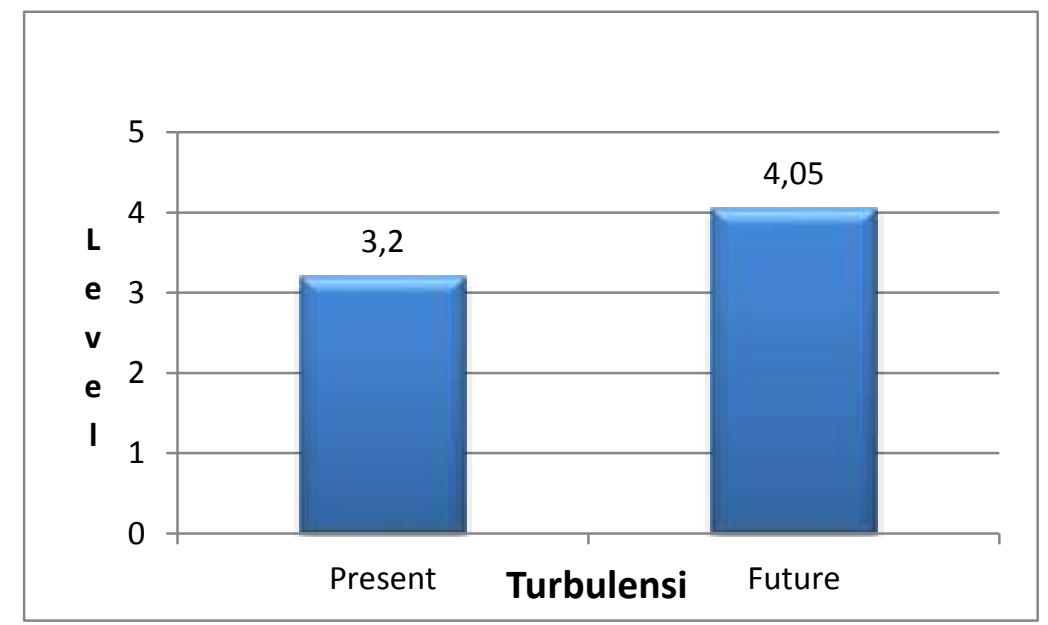

Survey untuk menentukan respon kapabiltas manajemen perusahaan dapat dilihat pada gambar dibawah.

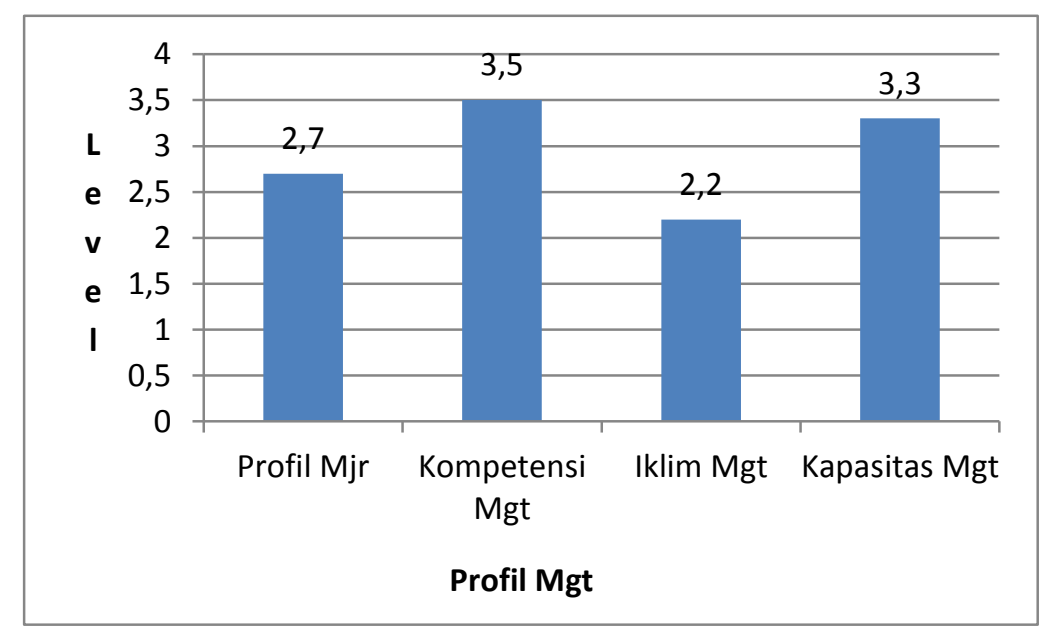

Apabila kita melihat analisa tersebut diatas, maka hubungan antara keduanya dapat digambarkan sebahai berikut : 


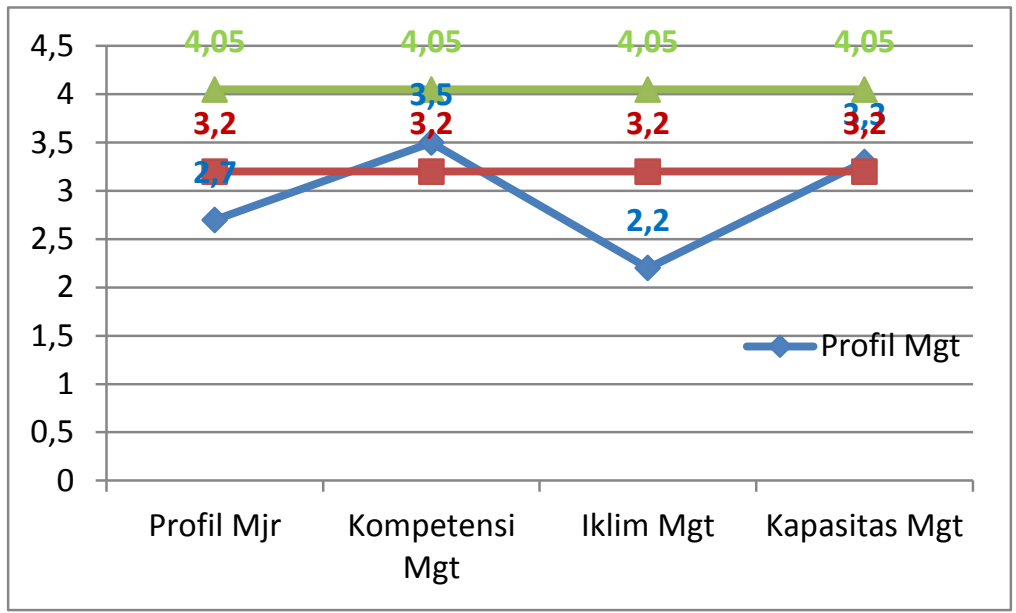

Grafik diatas menggambarkan hubungan antara turbulensi lingkungan dengan profil kapabilitas manajemen perusahaan, present turbulence sebesar 3.2, future turbulence 4.05 ini menggambarkan hasil matchup sbb :

Profil manajer berada pada level 2.7 menunjukan berada dibawah level present turbulence 3.2, berarti profil manajer yang berkaitan dengan SKA dan power, mentalitas untuk jangka pendek dan jangka panjang memerlukan perhatian yang serius.

Kompetensi Manajemen berada pada level 3.5 ini menunjukan bahwa kompetensi manajemen sudah dapat mengantisipasi perubahan lingkungan untuk kondisi saat ini, namun perlu ditingkatkan agar dapat merespon perubahan lingkungan masa mendatang (4.05).

Iklim Manajemen berada pada level 2.2 menunjukan bahwa memiliki level terendah dari semua profil manajemen, ini perlu perhatian khusus bagi manajemen puncak maupun manajemen lini, baik untuk masa kini maupun masa mendatang.

Kapasitas manajemen berada pada level 3.3 sudah menjawab tantangan turbulensi lingkungan sebesar 3.2, namun tetap memerlukan perhatian untuk jangka panjang karena masih dibawah future turbulence (4.05).

\section{KESIMPULAN DAN SARAN}

\section{Kesimpulan}

1) Profil Manajer berada dibawah level turbulensi sehingga memerlukan program perbaikan untuk mengatasi kelemahan pada profil manajer tersebut baik untuk masa kini maupun masa mendatang.

2) Kompetensi Manajemen menunjukan matchup dengan turbulensi present namun masih memerlukan pengembangan untuk mengantisipasi perubahan masa mendatang.

3) Iklim manajemen berada pada level 2.2 ini tidak mendukung terhadap perubahan tantangan lingkungan bisnis, sehingga memerlukan perhatian yang khusus dari manajemen setempat baik untuk transformasi budaya maupun pola kewenangan.

4) Kapasitas manajemen sudah melampui proses matchup berada pada level 3.3 namun tetap memerlukan program pengembangan untuk mengantisipasi perubahan lingkungan bisnis mendatang.

2. Saran

1) Perlu dilakukan pengukuran ulang untuk menentukan turbulensi lingkungan bisnis 
perusahaan secara komprehensif dan terprogram.

2) Perlu dilakukan identifikasi ulang terhadap profil kapabilitas manajemen perusahaan untuk mengantisipasi perubahan lingkungan bisnis baik untuk masa kini maupun untuk masa mendatang.

3) Perhatian khusus terhadap iklim manajemen karena belum dapat merespon perubahan lingkungan perusahaan, harus dicari akar permasalahannya apakah budaya pegawai belum dapat menyesuaikan perubahan lingkungan bisnis atau pola kewenangan yang perlu diperbaiki.

4) Hasil dari pengukuran ini perlu dilakukan feedback terhadap manajemen puncak dan para manajer lini.

5) Perlu dilakukan trial and error assessment profil kapabilitas manajemen perusahaan di divisi tertentu untuk di evaluasi dan dikembangkan ke divisi lainnya.

\section{DAFTAR PUSTAKA}

Australian Institute of Management. (2001). 2012 Australian Management Capability Index.

Hutabarat, Jemsly dan Martani Huseini (2006). Pengantar Strategik Manajemen Kontemporer (Strategik di Tengah Operasional). Jakarta: PT Gramedia

Umar Husein. (2001). Strategic Management in Action. Jakarta: PT Gramedia Pustaka Utama Capability management. Dapat diakses di http://en.wikipedia.org/wiki/Capability man agement\#Defence Lines of Development (diakses pada tanggal 20 Juli 2013) 